\title{
ENTOMOLOGY
}

\section{Drastic reduction in density of Blattella germanica and Periplaneta americana cockroaches after the application of fenitrothion and lindane in Dema, Zimbabwe}

\author{
N. Lukwa, ${ }^{1}$ T. Mduluza, ${ }^{2}$ C. Nyoni, ${ }^{3}$ M. Zimba ${ }^{4}$ \\ ${ }^{1}$ National Institute of Health Research, Harare; ${ }^{2}$ Department of Biochemistry, University of Zimbabwe, Harare; \\ ${ }^{3}$ Department of Social Work, Bindura University of Science Education, Bindura; ${ }^{4}$ Department of Biological Sciences, \\ University of Zimbabwe, Harare, Zimbabwe
}

\begin{abstract}
Field studies were conducted in villages near the peri urban Dema area, Seke district, Zimbabwe, in order to understand the effect of the insecticides fenitrothion and lindane on Periplaneta americana and Blattella germanica cockroaches. A total of 63, 72 and 71 rooms were used for control, fenitrothion and lindane respectively. The mean density per room for $P$. americana before spraying was $43.5,42.7$ and 44.1 for the control, fenitrothion and
\end{abstract}

Correspondence: Nzira Lukwa, National Institute of Health Research, P.O. Box CY573, Causeway, Harare, Zimbabwe.

E-mail: nziraa33@yahoo.co.uk

Key words: Blattella germanica, Periplaneta americana, cockroach, fenitrothion, lindane, infestation

Acknowledgements: We would like to acknowledge the householders who offered their houses to be used for research.

Contributions: NL designed the study, carried out research, wrote the paper, and submitted it for publication. TM designed the study, wrote the paper and analysed data. $\mathrm{CN}$ reviewed the paper and analysed data. $\mathrm{MZ}$ wrote the paper and analysed data.

Conflict of interest: the authors declare no potential conflict of interest.

Funding: none.

Received for publication: 11 January 2018.

Revision received: 15 March 2018.

Accepted for publication: 15 March 2018.

CCopyright N. Lukwa et al., 2018

Licensee PAGEPress, Italy

Journal of Entomological and Acarological Research 2018; 50:7291 doi:10.4081/jear.2018.7291

This article is distributed under the terms of the Creative Commons Attribution Noncommercial License (by-nc 4.0) which permits any noncommercial use, distribution, and reproduction in any medium, provided the original author(s) and source are credited. lindane respectively. The mean density per room for $B$. germanica before spraying was $51.4,50.2$ and 47.1 for the control, fenitrothion and lindane respectively. A reduction in population density of P. americana was $3.2 \%, 83.8 \%$ and $99.3 \%$ in the control, fenitrothion and lindane rooms respectively. A reduction in population density of $B$. germanica was $87.8 \%$ and $82.8 \%$ in fenitrothion and lindane rooms respectively. An increase of $9.9 \%$ in the control rooms was observed. The majority of $P$. americana cockroaches died one month post spray with fenitrothion killing $78.2 \%$ and lindane $37.4 \%$ of all cockroach collections. However, the number of dead B. germanica cockroaches was almost of the same order for fenitrothion $(71.9 \%)$ and lindane $(74.5 \%)$. The residual effect of fenitrothion was 3 months on both cockroach nymph species and that of lindane was 1 month. In conclusion, both fenitrothion and lindane had impact on cockroach density, and fenitrothion showed a residual effect of 3 months.

\section{Introduction}

Various reasons have been associated with the occurrence of cockroaches in households and institutions worldwide, depending on the location. However, the occurrence of cockroaches at household level has not been perceived as beneficial due the observed tendency to contaminate food and furniture with their droppings (Imamura et al., 2003). Infants and children have not been spared from the allergies associated with cockroach excreta (Yang et al., 2017). Several studies were conducted that documented the presence of medically important organisms in cockroaches. Cockroach control requires the use of baits (Durier and Rivault, 2003) and insecticides (Salehi et al., 2016).

Ameen et al. (2005) evaluated the efficacy of a $0.05 \%$ benzoyl-phenyl urea insect growth regulator (noviflumuron) against Blattella germanica cockroaches under laboratory conditions and results showed $100 \%$ nymphal mortality 120 days (4 months) after application. Fipronil caused $16-96 \%$ mortality of $P$. americana and $51-100 \%$ mortality of $B$. germanica cockroaches on different surfaces in a study conducted by Srinivasan et al. (2005). The laboratory study by Ameen et al. (2005) showed that noviflumuron reduced $B$. germanica population density by $51.9 \%$ (when applied at $0.05 \%$ ), 62.6\% (when applied at $0.1 \%$ ) and $62.6 \%$ (when applied at $0.2 \%$ ) 16 weeks post application (4 months). Field 
results of the same study showed a reduction of $73.3 \%$ when $0.2 \%$ noviflumuron and $90.6 \%$ when $0.5 \%$ noviflumuron were used (Ameen et al., 2005).

We carried out this study in order to understand how insecticides formulated with fenitrothion and gamma-hexa-chloro-cyclo-hexane (lindane) influence cockroach densities in real field settings.

\section{Materials and Methods}

\section{Study area}

Research was carried out in villages around Dema growth point, Seke district, Zimbabwe. The study area consists of brick houses that are roofed with asbestos sheeting as well as those made from bricks, mud plastered and containing thatched roofs. Most of the houses are close to each other and crop fields are located at a distance from residential houses. People are involved in subsistence farming and also maintain gardens.

\section{Insecticide formulation}

A $48.8 \%$ wettable powder formulation containing fenitrothion (organophosphate) constituted one insecticide and this insecticide is registered for use in Zimbabwe. Another wettable powder formulation containing 12\% gamma-hexa-chloro-cyclo-hexane (lindane) (organochlorine) was also used and this is also registered in Zimbabwe. Fenitrothion was prepared by mixing $100 \mathrm{~mL}$ of insecticide with 9.9L of water in a Hudson Xpert sprayer, mixing well before spraying inside walls and roofs of rooms. Lindane was prepared by mixing $375 \mathrm{~g}$ of insecticide with $9.625 \mathrm{~L}$ of water, shaking well before application.

\section{Field studies}

This study was designed in such a way that it was split into 2 parts; i) the study areas where insecticides were applied and taking account the control area and ii) an area where live cockroach nymphs and adults were being collected for bioassays on a monthly basis.

\section{Determination of population densities}

Pre-spraying exercises were conducted in order to determine the population densities of cockroaches (nymphs and adults) by placing attractant traps (350 ml bottles containing left over food) in food preparation rooms (kitchens or any other room where food was prepared). The presence of cockroaches was checked on the second day. All cockroaches (nymphs and adults) were morphologically identified and then a yellow tracing dye (powder form), consisting of a dyed/pigmented melamine, sulphonamide, copolymer was applied on them on the second day. These cockroaches were released at the centre of the village and re-trapping was done again. This process was repeated after the application of insecticides (3 months post spray) in order to measure changes in density. The mark-release-recapture population estimation technique by Southwood, (1966) was used. Population estimate of cockroaches was calculated using Southwood's formula (1966) as follows:

$P=\frac{M * C}{M^{\prime}}$

Where:

$\mathrm{P}=$ population estimate

$\mathrm{M}=$ number of cockroaches marked and released on day 1

$\mathrm{C}=$ number of cockroaches caught on day 2

$\mathrm{M}^{\prime}=$ number of marked cockroaches recaptured.

\section{Application of insecticides}

The walls and roofs of 63 rooms were sprayed with fenitrothion, 72 rooms with lindane (gamma-hexa-chloro-cyclo-hexane) and 71 rooms were not sprayed with insecticide and served as the control.

\section{Collection of cockroach nymphs for bioassays}

Live cockroach nymphs were collected using attractant traps as described in the population estimate method. These cockroach nymphs were kept in mosquito cages and were provided with leftover food until used. These cockroach nymphs were then used for monthly bioassays up to 3 months.

\section{Bioassays}

Bioassays were conducted on live cockroach nymphs collected from the second village using attractant traps by using 4 standard World Health Organization (WHO) cones per test measuring 8.5 $\mathrm{cm}$ in diameter at the base and $5.5 \mathrm{~cm}$ high. The cones were fixed on 4 different positions on the walls of rooms, and then 10 cockroach nymphs were placed inside them and exposed for $30 \mathrm{~min}$ utes. The cockroach nymphs were retrieved and kept in $150 \mathrm{~mL}$ glass bottles for $24 \mathrm{hrs}$. Bioassays were done monthly.

\section{Data analysis}

The data was entered in an EXCEL sheet and analysed using ANOVA (Analysis of variance) method. Significant differences were determined at $95 \%$ confidence limit.

\section{Results}

\section{Population densities}

The application of any of the 2 insecticides resulted in drastic changes in population density per room, irrespective of the species of cockroaches during field studies (Table 1). The population densities of cockroaches were not significantly different at the start of the study for all treatments, including the control $(\mathrm{P}=0.4)$. There was a slight decrease in $P$. americana cockroach density in the control and a slight increase in the density of $B$. germanica cockroaches in the control rooms. The percentage reduction in population densities of either P. americana or B. germanica after the application of either insecticides was of the same magnitude, with no significant difference observed $(\mathrm{P}=0.6)$, although significant difference was seen when the controls were considered together with treatments $(\mathrm{P}=0.001)$. However, the actual density of $P$. americana after the application of lindane was the lowest and significantly different $(\mathrm{P}=0.03)$.

The overall composition of cockroaches before the application of insecticides showed that species diversity constituted $46.7 \% P$. americana and $53.3 \%$ B. germanica. However, after the application of insecticides, $P$. americana constituted $41 \%$ (a reduction of $5.7 \%$ ) and B. germanica 59\% (an increase of 5.7\%). P. americana in the control rooms at the start of the study constituted $50.8 \%$ of all cockroaches and this decreased to $49.2 \%$ after 3 months. The trend for $B$. germanica in the control rooms showed a start of $47.6 \%$ and this shifted to $52.4 \%$ (4.8\% increase) after 3 months later. Treated rooms showed a totally different scenario whereby rooms treated with fenitrothion had $88.1 \%$ P. americana before application of insecticide and this was reduced to $11.9 \%$ (reduction of $76.2 \%$ ) three months later and this trend was similar with $B$. germanica $(89.2 \%$ before spraying and $10.8 \%$ after spraying) (reduction of $78.4 \%$ after spraying). Lindane showed a larger change in 
P. americana composition $(99.1 \%$ before spraying and $0.9 \%$ after spraying) (98.2\% reduction) and this trend was similar with $B$. germanica cockroaches $(85.3 \%$ before spraying and $14.7 \%$ after spraying) (70.6\% reduction).

\section{Effect of insecticides on cockroach mortality in field studies}

Over $70 \%$ of either $P$. americana or B. germanica cockroaches were collected dead from rooms where fenitrothion was applied, 1 month post spray (Table 2). On the other hand, few dead P. americana cockroaches were collected from rooms were lindane was applied and the percent mortality was almost of the same magnitude. The effect of lindane on $B$. germanica cockroaches was almost the same with that of fenitrothion for 3 months. A negligible proportion of $P$. americana cockroaches were collected dead from control rooms. The total number of dead $P$. americana cockroaches was 5392, 3571 and 3158 for the control, fenitrothion and lindane rooms respectively. The total number of dead B. germanica cockroaches was 6798, 4053 and 3919 for the control, fenitrothion and lindane rooms respectively.

\section{Residual effect of insecticides on cockroach nymphs}

All insecticides offered $100 \%$ mortality on both cockroach species one month post spray (Table 3). Fenitrothion killed more $P$. americana cockroaches than lindane 2 months post spray and the results were significantly different $(\mathrm{P}=0.04)$ and this was the same with $B$. germanica $(\mathrm{P}=0.043)$. Complete mortality occurred for both cockroach nymph species when exposed to rooms sprayed with fenitrothion, giving a residual effect of 3 months and this was not realized with lindane. On the other hand, rooms sprayed with lindane showed a residual effect of 1 month on either $P$. americana or $B$. germanica cockroach nymphs.

\section{Discussions and Conclusions}

\section{Population densities}

Results in this study have shown that the starting baseline was not significantly different in terms of either P. americana or B. germanica cockroach density, with distinct composition levels of $P$. americana and $B$. germanica. This puts all the 3 treatments at the same level before the study commenced. The impact of insecticides on population densities of both cockroach species showed a marked reduction after application as compared with the control. The highest reduction in cockroach density was recorded in rooms that were sprayed with lindane (on P. americana), followed by fenitrothion (on B. germanica), fenitrothion (on P. americana) and lastly lindane (on $B$. germanica). Under natural behaviour, it

Table 1. Cockroach densities per room before and after application of insecticides during field studies.

\begin{tabular}{|c|c|c|c|c|c|c|c|c|c|c|c|c|}
\hline & \multicolumn{5}{|c|}{ P. americana cockroaches } & \multicolumn{6}{|c|}{ B. germanica cockroaches } \\
\hline & & Control & & othion & & Lindane & & Control & & trothion & & Lindane \\
\hline & N. & $\begin{array}{l}\text { Density } \\
\text { /room }\end{array}$ & N. & $\begin{array}{l}\text { Density } \\
\text { /room }\end{array}$ & N. & $\begin{array}{l}\text { Density } \\
\text { /room }\end{array}$ & N. & $\begin{array}{l}\text { Density } \\
\text { /room }\end{array}$ & N. & $\begin{array}{l}\text { Density } \\
\text { /room }\end{array}$ & N. & $\begin{array}{l}\text { Density } \\
\text { /room }\end{array}$ \\
\hline Before spraying & 2740 & $43.5^{\mathrm{a}}$ & 3074 & $42.7^{\mathrm{a}}$ & 3131 & $44.1^{\mathrm{a}}$ & 3238 & $51.4^{\mathrm{a}}$ & 3614 & $50.2^{\mathrm{a}}$ & 3344 & $47.1^{\mathrm{a}}$ \\
\hline 3 months after spraying & 2652 & $42.1^{\mathrm{a}}$ & 497 & $6.9^{\mathrm{b}}$ & 27 & $0.3^{c}$ & 3560 & 56.5 & 439 & $6.1^{\mathrm{b}}$ & 575 & $8.1^{\mathrm{b}}$ \\
\hline Change & 88 & 1.4 & 2578 & 35.8 & 3111 & 43.8 & 321 & -5.1 & 3175 & 44.1 & 2769 & 39.0 \\
\hline$\%$ change & & $\begin{array}{c}3.2 \% \mathrm{~b} \\
\text { (reduction) }\end{array}$ & & $\begin{array}{c}83.8^{\mathrm{a}} \\
\text { (reduction) }\end{array}$ & & $\begin{array}{c}99.3 \% \%^{\mathrm{a}} \\
\text { (reduction) }\end{array}$ & & $\begin{array}{c}-9.9 \% \mathrm{~b} \\
\text { (increase) }\end{array}$ & & $\begin{array}{c}87.8 \%{ }^{\mathrm{a}} \\
\text { (reduction) }\end{array}$ & & $\begin{array}{c}82.8 \%{ }^{\mathrm{a}} \\
\text { (reduction) }\end{array}$ \\
\hline
\end{tabular}

Same letter in the same row shows no significant difference. Different letter in the same row shows significant difference.

Table 2. Total number of dead cockroaches during field studies (number of dead cockroaches is shown and percent of all cockroaches over the 3 months period is in brackets).

\begin{tabular}{lcccccc} 
Month post spray & \multicolumn{3}{c}{$\begin{array}{c}\text { P. americana cockroaches } \\
\text { Control (\%) }\end{array}$} & $\begin{array}{c}\text { Fenitrothion (\%) } \\
\text { Lindane (\%) }\end{array}$ & Control (\%) & $\begin{array}{c}\text { B. germanica cockroaches } \\
\text { Fenitrothion (\%) }\end{array}$ Lindane (\%) \\
1 & $0(0)^{\mathrm{a}}$ & $4051(78.2)^{\mathrm{b}}$ & $12(37.4)^{\mathrm{c}}$ & $0(0)^{\mathrm{a}}$ & $3863(71.9)^{\mathrm{b}}$ & $651(74.5)^{\mathrm{b}}$ \\
2 & $0(0)^{\mathrm{a}}$ & $1122(21.6)^{\mathrm{b}}$ & $10(31.3)^{\mathrm{b}}$ & $0(0)^{\mathrm{a}}$ & $1211(22.5)^{\mathrm{b}}$ & $206(23.6)^{\mathrm{b}}$ \\
\hline 3 & $1(0.04)^{\mathrm{a}}$ & $11(0.2)^{\mathrm{a}}$ & $10(31.3)^{\mathrm{b}}$ & $0(0)^{\mathrm{a}}$ & $302(5.6)^{\mathrm{a}}$ & $17(1.9)^{\mathrm{a}}$ \\
Total & $1(0.02)$ & $5184(100)$ & $32(100)$ & $0(0)$ & $5376(100)$ & $874(100)$ \\
\hline
\end{tabular}

Same letter in the same row shows no significant difference. Different letter in the same row shows significant difference.

Table 3. Residual effect of fenitrothion and lindane on P. americana and B. germanica cockroach nymphs (number of dead cockroach nymphs is indicated with percent mortality in brackets).

\begin{tabular}{|c|c|c|c|c|c|c|}
\hline \multirow{2}{*}{ Month post spray } & \multicolumn{3}{|c|}{ P. americana cockroach nymphs } & \multicolumn{3}{|c|}{ B. germanica cockroach nymphs } \\
\hline & Control (\%) & Fenitrothion (\%) & Lindane (\%) & Control $(\%)$ & Fenitrothion (\%) & Lindane $(\%)$ \\
\hline 1 & $0(0)^{\mathrm{a}}$ & $40(100)^{b}$ & $40(100)^{b}$ & $0(0)^{\mathrm{a}}$ & $40(100)^{b}$ & $40(100)^{b}$ \\
\hline 2 & $0(0)^{\mathrm{a}}$ & $40(100)^{b}$ & $18(45)^{\mathrm{c}}$ & $0(0)^{\mathrm{a}}$ & $40(100)^{b}$ & $22(55)^{\mathrm{c}}$ \\
\hline 3 & $0(0)^{\mathrm{a}}$ & $40(100)^{b}$ & $3(7.5)^{\mathrm{c}}$ & $0(0)^{\mathrm{a}}$ & $40(100)^{b}$ & $5(12.5)^{\mathrm{c}}$ \\
\hline
\end{tabular}

Same letter in the same row shows no significant difference. Different letter in the same row shows significant difference. 
would have been expected that cockroaches emigrated to nonsprayed areas due to the nature of insecticides, this is an unlikely event. Our results on the reduction of cockroach density due to the application of insecticides were higher than those recorded by Ameen et al. (2005) on laboratory studies 16 weeks (4 months) post application although field studies showed better results.

Interestingly, our results have shown that insecticides can impact greatly on certain cockroach species than others, showing some selectivity. The reduction in cockroach density by fenitrothion 3 months post spray was experienced at different levels, with more reduction in $B$. germanica than $P$. americana and this was the same with lindane. Our results have shown that the natural species composition in the study area has more $B$. germanica than $P$. americana cockroaches. Such difference in species diversity may indicate that it might not be always possible to extrapolate such results for sites that are totally different, with totally different ecological settings.

Our results have also shown that the level of species diversity may be influenced by control measures instituted, as shown by a reduction of $P$. americana and increase in $B$. germanica after spraying. These results may be linked with the possibility of emigration tendencies of cockroaches that might occur due to various reasons. These results were confirmed in control rooms that showed a similar trend, although this appeared to be species specific. Studies by Durier and Rivault, (2003) and Salehi et al. (2016) have shown that the application of baits and insecticides have impact on cockroach infestation and our results agree with these findings. Our results have demonstrated that application of insecticides in rooms may result in meaningful changes in P. americana and B. germanica cockroach densities.

\section{Residual effect in the field}

Our bioassay results have shown that application of fenitrothion had a residual effect of 3 months on both $P$. americana and $B$. germanica cockroach nymphs, implying that this insecticide can be applied once every 3 months. The results on mortality rate of $B$. germanica after application of fenitrothion were not as good as those observed by Ameen et al. (2005) on the same cockroach species. On the other hand, lindane had a residual effect of one month on both $P$. americana and $B$. germanica cockroach nymphs. In conclusion, both fenitrothion and lindane had impact on cockroach density, and fenitrothion showed a residual effect of 3 months.

\section{References}

AMEEN A., WANG C., KAAKEH W., BENNETT G.W., KING J.E., KARR L.L. XIE J. 2005 - Residual activity and population effects of noviflumuron for German cockroach (Dictyoptera: Blattellidae) control. J. Econ. Entomol. 98: 899-905.

DURIER V., RIVAULT C. 2003 - Improvement of German cockroach (Dictyoptera: Blattellidae) population control by fragmented distribution of gel baits. J. Econ. Entomol. 96: 1254-8.

IMAMURA S., KITA M., YAMAOKA Y., YAMAMOTO T., ISHIMARU A., KONISHI H., WAKABAYASHI N., MITSUFUJI S., OKANOUNE T., IMANISHI J. 2003 - Vector potential of cockroaches for Helicobacter pylori infection. Am. J. Gastroenterol. 98: 1500-3.

SALEHI A., VATANDOOST H., HAZRATIAN T., SANEIDEHKORDI A., HOOSHYAR H., ARBABI M., SALIMABADI Y., SHARAFATI-CHALESHTORI R., GOROUHI M.A., PASKA A. 2016 - Detection of bendiocarb and carbaryl resistance mechanisms among German cockroach Blattella germanica (Blattaria: Blattellidae) collected from Tabriz Hospitals, East Azerbaijan Province, Iran in 2013. J. Arthropod Borne Dis. 10: 403-12.

SOUTHWOOD T.R.E. 1966 - Ecological methods with particular reference to the study of insect populations. Methuem and Co London.

SRINIVASAN R., JAMBULINGAM P., SUBRAMANIAN S., KALYANASUNDARAM M. 2005 - Laboratory evaluation of fipronil against Periplaneta americana \& Blattella germanica. Indian J. Med. Res. - 122: 57-66.

YANG C.F., YANG C.C., WANG I.J. 2017 - Association between allergic diseases, allergic sensitization and attentiondeficit/hyperactivity disorder in children: A large-scale, population-based study. J. Chin. Med. Assoc. S1726-4901: 3030-40. 